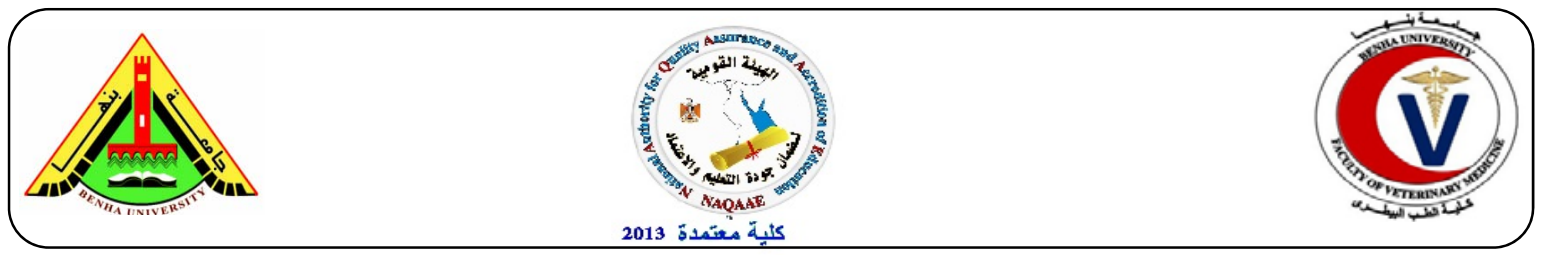

\title{
Preliminary studies on $E$. Coli implicated in avian Colibacillosis with reference to their antibiotic resistance profiles
}

\author{
Ashraf A. Abd El Tawab ${ }^{1}$, Ahmed M. Ammar ${ }^{2}$, Fatma I. El-Hofy ${ }^{1}$, Mokhtar Abdel Hakeem ${ }^{3}$ and \\ Noha M. Abdel Galil ${ }^{3}$ \\ ${ }^{1}$ Bacteriology, Immunology and Mycology Dept. Fac. Vet. Med., Benha Univ., ${ }^{2}$ Bacteriology, \\ Immunology and Mycology Dept., Fac. Vet. Med. Zagazig Univ. ${ }^{3}$ Animal Health Research Institute \\ (Zagazig branch).
}

\begin{abstract}
A B S T R A C T
Colibacillosis constituted as one of the most important disease condition affecting poultry with significant implications on production. Herein, examination of 451 organ samples including trachea, lung, heart blood, liver and spleen collected from freshly slaughtered chickens using standard methods for isolation and identification of E. coli showed that 236 samples were positive for $E$. coli with an incidence rate (52\%). Twenty-five E. coli strains were serogrouped and 6 different serogroups were successfully identified, the most prevalent serogroup was O78 (20\%), followed by O157 and O27 with incidence rate $(16 \%)$ for each, $\mathrm{O} 168$ and $\mathrm{O} 125(12 \%)$ each. and finally $\mathrm{O} 115(8 \%)$, in addition to 4 untypable strains. The antibiotic susceptibility of 60 isolates against ten antimicrobials was performed by disc diffusion method and the results revealed that gentamicin and colistin were the most effective antibiotics on the isolates. On the other hand, all isolates exhibited absolute resistance to erythromycin and rifampicin, followed by high level of resistance ranging from (75-95\%) for ciprofloxacin, sulfamethoxazole-trimethoprim, cefoxtin, chloramphenicol, doxycycline and amoxicillin- clavulanic acid. All isolates exhibited multidrug resistance phenotypes.
\end{abstract}

Key words: Escherichia coli, Biochemical identification, Serogrouping, Antibiotic resistance.

(http://www.bvmj.bu.edu.eg)

(BVMJ-30(1): 68-77, 2016)

\section{INTRODUCTION}

$E$ scherichia coli is the most common etiological agent involved in many disease conditions in poultry (Barnes et al., 2008). Although E. coli presents as normal microflora in the intestinal tract of chickens, extra intestinal pathogenic E. coli (ExPEC) infections generates a negative economic impact (Barnes et al., 2003 and Mellata, 2013). The subpathotype of ExPEC that infects poultry causing collibacillosis, known as avian pathogenic E. coli (APEC) and is considered a heterogeneous group of pathogens present in all stages of the poultry production chain, causing several types of lesions and diseases (Cunha et al., 2014). This infectious disease is considered to be initiated in the avian upper respiratory tract; air sacs being the first organs infected, followed by septicemia and organ colonization (Germon et al., 2005 and Saberfar et al., 2008). APECs have diverse serotypes, but certain ones $(\mathrm{O} 78, \mathrm{O} 2$, and O1) are more frequently observed than others (Jeong et al., 2012). The frequencies of O78 among APEC isolates vary according to location and host (Ewers et al. 2004). Antimicrobial therapy is one of the primary control measures for reducing the morbidity and mortality caused by APEC infections. In the latest decades, an increasing resistance against various classes of antibiotics has become exaggerated due to the excessive and misuse of antibiotics either as treatment or as growth promoters (Teuber, 2001). That represents a serious 
danger to poultry industry and consequently to human health (Piddock, 1996) so they need to be used prudently in order to preserve their therapeutic usefulness in both animals and humans (Gyles, 2008). The development and dissemination of antibacterial resistance had become a topic of concern due to its direct influence on public health, through elevating the morbidity, mortality, and treatment costs of infectious diseases. In view of these considerations, the present study was undertaken for isolation and identification of $E$. coli to record the prevalence of $E$. coli infection in chickens and serotyping of the obtained isolates then performing the antibiogram susceptibility test on the isolates.

\section{MATERIAL AND METHODS}

\subsection{Samples collection:}

Four hundred and fifty-one tissue specimens including tracheas, lungs, heart blood, livers and spleens of freshly slaughtered broilers showing different disease manifestations clinically diagnosed as colibacllosis and obtained from farms of different localities in Sharkia (103) and Dakahlia (56) Governorates, were submitted to the bacteriological examination for $E$. coli isolation.

\subsection{Isolation and identification of E. coli (Cruickshank et al. 1975):}

The surface of organs was seared by hot spatula, and then a sterilized loopfuls were inoculated onto MacConkey's broth and incubated aerobically at $37^{\circ} \mathrm{C}$ for 12 hours. Loopfuls from incubated MacConkey's broth were streaked onto MacConkey's agar plates and incubated for 24 hours at $37^{\circ} \mathrm{C}$. Suspected lactose fermented colonies (pink colonies) were picked up and streaked on the eosin methylene blue (EMB) then incubated for another $24-48$ hours at $37^{\circ} \mathrm{C}$. The suspected purified colonies were picked up for examination by IMVC and TSI biochemical tests, followed by typing of the isolates by RapID ${ }^{\mathrm{TM}}$ ONE system
(Remel), which is a qualitative micro method employing conventional and chromogenic substrate for the identification of medically important Enterobacteriaceae and other selected oxidase-negative, Gnegative bacilli by following the kit manual instructions.

\subsection{Serological typing of E. coli}

Twenty-five isolates that were preliminary identified as E. coli, were taken randomly and subjected to serological identification (Edward and Ewing, 1972) using slide agglutination test.

\subsection{Antimicrobial susceptibility testing}

Antibiotic susceptibilities of $E$. coli isolates were determined by the standard disk diffusion method (Finegold and Martin, 1982), E. coli isolates were tested against the following antimicrobial agents: gentamicin, rifambicin, ciprofloxacin, colistin, amoxicillin-clavulanic acid, cefoxtin, doxycyclin, chloramphenicol, erythromycin and sulfamethoxazoletrimethoprim.

\section{RESULTS}

3.1. The total Recovery rate of $E$. coli isolated from different organs in broilers:

The obtained results revealed that 236 isolates were identified as $E$. coli with percentage of $52.3 \%$ distributed as $(64 \%$, $51 \%, 48 \%, 52 \%$ and $41 \%$ out of the examined lung, liver, heart blood and trachea and spleen, respectively. with a total number of $145(56.6 \%)$ and $101(51.8 \%) E$. coli isolates out of 256 and 195 examined specimens from Sharkia and Dakalia Governorates, respectively as shown in Table (1).

\subsection{Serological typing of E. coli isolates:}

The results of serological identification of 25 E. coli Isolates revealed that $\mathrm{O} 78$ was the most predominant serotype with a percentage of $(20 \%)$ followed by $\mathrm{O} 157$ and $\mathrm{O} 27$ (16\%) each, other serotypes as O168, 
Table (1): The total recovery rate of $E$. coli isolated from different organs in broilers.

\begin{tabular}{cccc}
\hline $\begin{array}{c}\text { Organ } \\
\text { Specimen }\end{array}$ & $\begin{array}{c}\text { Examined } \\
\text { No. }\end{array}$ & $\begin{array}{c}\text { Positive } \\
\text { No. }\end{array}$ & Percent \\
\hline Lung & 100 & 64 & $64 \%$ \\
Liver & 100 & 51 & $51 \%$ \\
Heart blood & 100 & 48 & $48 \%$ \\
Trachea & 100 & 52 & $52 \%$ \\
Spleen & 51 & 21 & $41 \%$ \\
Total & 451 & 236 & $52 \%$ \\
\hline
\end{tabular}

Table (2): The incidence and frequency distribution of $E$. coli serogroups

\begin{tabular}{ccc}
\hline $\begin{array}{c}\text { E. coli } \\
\text { Serogroup }\end{array}$ & $\begin{array}{c}\text { No. of } \\
\text { isolates }\end{array}$ & Percent \\
\hline & 5 & $20 \%$ \\
O78 & 4 & $16 \%$ \\
O27 & 4 & $16 \%$ \\
O157 & 3 & $12 \%$ \\
O168 & 3 & $12 \%$ \\
O125 & 2 & $8 \%$ \\
O115 & 4 & $16 \%$ \\
Untypable & & \\
\hline
\end{tabular}

Table (3): Resistance Profile of the E. coli isolates against ten antimicrobial agents

\begin{tabular}{ccc}
\hline \multirow{2}{*}{$\begin{array}{c}\text { Antimicrobial } \\
\text { Agents }\end{array}$} & \multicolumn{2}{c}{$\begin{array}{c}\text { E. coli Isolates } \\
(60)\end{array}$} \\
\cline { 2 - 3 } & No. & \multicolumn{2}{c}{$(\%)$} \\
C & 50 & $83 \%$ \\
CT & 27 & $45 \%$ \\
AMC & 45 & $75 \%$ \\
E & 60 & $100 \%$ \\
FOX & 51 & $85 \%$ \\
CN & 24 & $40 \%$ \\
CIP & 57 & $95 \%$ \\
RF & 60 & $100 \%$ \\
SXT & 56 & $93 \%$ \\
DO & 48 & $80 \%$ \\
\hline
\end{tabular}

(AMA): Antimicrobial agents; (C): chloramphenicol, (cT): colistin, (AMC): amoxicillin- clavulanic acid; (E): erythromycin; (FOX): cefoxtin; (CN): gentamicin; (CIP): ciprofloxacin; (RF): rifambicin; (SXT): sulfamethoxazole-trimethoprim and (DO): doxycyclin. 
Table (4): Prevalence of the multidrug resistant E. coli isolates

\begin{tabular}{cc}
\hline No. of antimicrobial agents & No. of E. coli isolates \\
\hline Three drugs & 1 \\
Four drugs & 0 \\
Five drugs & 4 \\
Six drugs & 3 \\
Seven drugs & 10 \\
Eight drugs & 12 \\
Nine drugs & 21 \\
Ten drugs & 9 \\
\hline
\end{tabular}

O125 were also recorded with percentage of $(12 \%)$ each, and $\mathrm{O} 115$ with percentage of $(8 \%$ (while, 4 isolates were untypable. As shown in Table (2).

\subsection{Antimicrobial susceptibility testing:}

The results revealed that all isolates showed absolute resistance to rifambicin and erythromycin $(100 \%)$ followed by high frequencies of resistance observed to ciprofloxacin, sulfamethoxazole/ trimethoprim ( $95 \%$ and $93 \%$, respectively). The resistance to cefoxtin was $(85 \%)$, chloramphenicol (83\%), doxycycline $(80 \%)$ and amoxicillin/ clavulanic acid (75\%). Meanwhile, least level of resistance in E. coli isolates was reported to colistin and gentamycin (45\% and 40\%), respectively as shown in Table (3). Additionally, no isolate was completely sensitive to all antibiotics while high level of multidrug resistance was reported, 9 isolates were resistant to ten antimicrobial agents tested, 21 were resistant to 9 antimicrobial agents and 12 isolates were resistant to 8 antimicrobial agents. None of the tested antibiotics showed $100 \%$ efficacy on all isolates, as shown in Table (4).

\section{DISCUSSION}

APEC causes avian colibacillosis, a disease of poultry that occurs worldwide and associated with heavy economic losses (Barnes et al., 2008). APEC identification has passed through a number of developments, beginning with conventional methods of identification based on chemical characterization and the nature of selective media. A more specific identification approach is the serotyping analysis that aims at classifying pathogenic strains based on their surface antigens. Based on $\mathrm{O}, \mathrm{H}$, and $\mathrm{K}$ antigens. $\mathrm{O}$ Serogrouping is one of the basic diagnostic methods for the classification of pathogenic strains of $E$. coli. It is suggested that some strains $(\mathrm{O} 1$, $\mathrm{O} 2$ and $\mathrm{O} 78$ ) could be classified as avian pathogenic strains (Giovanardi et al., 2005, Kawano et al., 2006, Yaguchi et al., 2007, Ozawa et al., 2008). In the present investigation, out of 451 examined tissue specimens representing different organs collected from freshly slaughtered diseased broilers, results revealed that $E$. coli were recovered from 236 samples with an overall prevalence rate $(52 \%)$. Nearly similar results were recorded in other studies in Egypt as those of Sharada et al., (2010); Norhan (2011); Wafaa (2012) and Ammar et al., (2015) who isolated E. coli from diseased broilers with total recovery rates $(44.6 \%, 63.6 \%, 46.6 \%$ and $63.0 \%)$, respectively. Higher recovery rates were recorded in a previous study carried out by Abd El Aziz et al. (2007) who isolated E. coli from different poultry farms showing signs of CRD in Dakahlia governorate with percentage of $(90 \%)$. In addition to Nashwa et al., (2010) and Shimaa (2013) who isolated E. coli with percentage of $(75 \%)$ each and Samanta et al. (2014) (75.5\%) from backyard chicken in India. However, 
lower isolation rate was reported by Momtaz et al. (2012) (15.8\%). Moreover, the highest isolation rate of $E$. coli was from lung $(64 \%)$ followed by trachea $(52 \%)$; liver (51\%); heart blood (48\%) and finally spleen with incidence rate (41\%). The high isolation rate from lung and trachea may be attributed to the fact that the infection usually begins at the respiratory tract and then spread to other internal organs resulting in systemic infection. (Barnes et al., 1999). The biochemical profile of $E$. coli isolates was similar to those previously reported such as fermentation of certain sugars or enzymatic reaction (Gomis et al., 2001; Quinn et al., 2002; Bopp et al., 2005 and Raji et al., 2007). It has been suggested that high metabolic activity might be characteristic of highly virulent strains associated with colibacillosis (LeBouguenec and Schouler, 2011).

Concerning identification of isolates depending on RapID one identification system (Remel). E. coli strains belonged to four profiles (4361011, 4161001, 0261001 and 4341011) this is in accordance with previous studies which proved accuracy rate for this test exceeding $91 \%$ in identification of Enterobacteriaceae (Kitch et al., 1994 and Lee et al., 1994).

In the present study, 25 of the obtained $E$. coli isolates recovered from broilers with different disease manifestations were serotyped by slide agglutination test. The results showed that $\mathrm{O} 78$ was the most predominant serogroup with a percentage $20 \%$, followed by O157 and O27 with percentage 16\%; O168, respectively and O125 (12\%); finally, O115 (8\%). While 4 other strains were untypable. These results are in line with those recorded by Zhao et al., (2005) and Jin et al., (2008) who stated that the most common E. coli serotype in avian colibacillosis cases was $\mathrm{O} 78$ and McPeake et al., (2005) who recovered E. coli $\mathrm{O} 78$ serogroup from cases of colisepticaemia in broilers with a percentage of $55 \%$. In addition to Kumar et al., (2003) who found that the most predominant APEC serogroups were O78
$(23.5 \%)$. Also, these results go hand in hand with those recorded by Wen-Jie et al., (2008) who reported that the most prevalent APEC serotype isolated from poultry with colibacillosis in different areas of China was $\mathrm{O} 78(17.6 \%)$. In addition, other serotypes as, $\mathrm{O} 115$ was also recorded, Rezk et al., (2010) detected E. coli O78 and O125 serogroups in diseased chickens collected from different localities in Ismailia Governorate and Al-Ajimi (2011) who isolated APEC O125 serotype from lung of broilers. Shimaa and Mosalem (2013) obtained similar results and isolated E.coli O78, O157, O125 and other serogroups from sever outbreaks of $E$. coli. These variations indicated that $E$. coli serogroups are country specific, which is important in bacerines preparation that must be specific to the predominant serogroup. Antimicrobial agents have been widely used in poultry to treat infections caused by a variety of bacterial pathogens. However, this wide spread use of large quantities of antimicrobials in poultry without professional supervision causes many problems. Furthermore, the use of antibiotics as growth promoters in poultry feed for the last 60 years (Aarestrup, 2005) led to development of antimicrobial resistance and zoonotic transfer of antibiotic resistance genes resulted in prevention of antibiotic usage as growth promotors in Europe (Castanon, 2007). Antibiotic susceptibility test was performed on $60 \mathrm{E}$. coli isolates using disc diffusion method to determine the differentiation between the isolates according to variation in their inhibition to different antibiotics. The results revealed that all the isolates were resistant to rifampicin and erythromycin $(100 \%)$ followed by high frequencies of resistance to ciprofloxacin and sulfamethoxazole/ trimethoprim (95\% and $93 \%$, respectively). Resistance to cefoxtin, chloramphenicol, doxycycline and amoxicillin-clavulinic acid were $(85 \%$, $83 \%, \quad 80 \%$ and $75 \%$ ), respectively. Meanwhile, the least level of resistance was reported to colistin (45\%) and gentamicin 
with (40\%). Additionally, no isolate was completely sensitive to all the antibiotics. Gentamycin and colistin were the most effective chemotherapeutic agents on the tested isolates, and similar finding was reported by Blanco et al. (1996) who found that colistin was one of the antibiotics that showed low level of resistance against $E$. coli isolates. High level of erythromycin resistance was also reported in many previous studies as Nazir, 2004; Afshin and Kashefi, 2012; Ezzeldeen et al., 2013 and Rahimi, 2013) who reported resistance rate to erythromycin with percentage of $92.3 \%$, $100 \%, 100 \%$ and $96.1 \%$, respectively. As well as a very high level of resistance to chloramphenicol was detected by other investigators (Islam et al., 2004 and Rahman et al., 2008). In the existing study, a very high level of multidrug resistant $E$. coli isolates was recorded, similar findings had been reported before in different parts of the world (Amara et al., 1995; Guerra et al., 2003; Saenz et al., 2003; Rahman et al., 2008 and Rahimi, 2013). Yet it was higher than those reported by other researchers in European countries (Blanco et al., 1996 and David and Burch, 2000). According to Pessanha et al., (2001) broilers can act as reservoirs of important antibiotic resistance genes in veterinary and human medicine and the use of growth promoters in animal feed may contribute to the occurrence of multidrug resistant isolates as well.

\section{CONCLUSION}

In conclusion, the current study showed that multidrug resistant $E$. coli isolates are prevalent among broilers. The increase and spread of multidrug resistance is alarming so it is important to understand the mechanism of resistance of bacteria to antibiotic to be able to overcome it. Besides there should be a renewed interest for the development of new derivatives and generations of antibiotics. safety measures as strict biosecurity, correct management and effective vaccination programs should be employed and limiting the random use of antibiotics in the veterinary field.

\section{REFERENCES}

Aarestrup, F.M. 2005.Veterinary drug usage and antimicrobial resistance in bacteria of animal origin. Basic clin. Pharmacol. Toxicol. 96: 271-281.

Abd El-Aziz, E.E., Hassan, A.M., Badr, J.M. 200. In vitro efficacy of some cases of chronic respiratory disease in broilers in Egypt. Zag. Vet. J. 35(3):40-49.

Afshin, Z., Kashefi, P. 2012. Antimicrobial susceptibilities of avian E. coli isolates in Tabriz, Iran. African Biotechnology J. 11 (19): 4467-4470.

Al-Ajimi, A.D. 2011. Escherichia coli isolated from broiler farms with special references to virulence genes of isolated strains. M. V. Sci. Thesis, Microbiology Department, Faculty of Vet. Med., Zagazig University.

Amara, A., Ziani, Z. Bouzoubaa, K. 1995. Antibiotic resistance of Escherichia coli strains isolated in Morocco from chickens with colibacillosis. Veterinary Microbiology J. 43: 325-330.

Ammar, A.M., Ahlam, A. G., Hanaa, K.A., Norhan, K. A., Amira, E.1. 2015. Macrolide resistance of Mycoplasma gallisepticum and Escherichia coli accused of chronic respiratory disease in chickens. Zag. Vet. J. 2(43):1-12.

Barnes, H.J., Gross, W.B., Colibacillosis. In: Calnek, B.W.; Beard, C.W., McDougald, L.M. Saifin, Y.M. (1999): editors. Dis. of poult. Ames:Iowa State University Press; 131-141.

Barnes, H.J., Nolan, 1.k., vaillancourt, J.A. 2008. Colibacillosis in Saif, Y.M., Fadly, A.M. (Eds.), Disease of poultry. Blackwell Publishing, Ames, IA PP.691-732. 
Barnes, H.J., Vaillancourt, J., Saif, Y.M., Gross, W.B. 2003. Colibacillosis, Iowa State University Press, Ames, Iowa, USA. Dis. of Poul. j., 631-652.

Blanco, J.E., Blanco, M., Mora, A., Coroas, C., Blanco, J. 1996. E. coli associated with colisepticaemia in Spain. Medicina Veterinaria.13

(12): 680-686.

Bopp, C.A., Brenner, F.W., Wells, J.G., Strockbine, N.A. 2005. Escherichia, Shigella and Salmonella. In: Manual of Clinical Microbiology. (Murray, P. R., E.J. Baron, M.A. Pfaller, F.C. Tenover, R.H. Yolken, Eds.). American Society for Microbiology, Washington, DC. 459- 474.

Castanon, J.I. 2007. History of the use of antibiotic as growth promotors in Euoropean poultry feeds, Poult. Sci. 86, 2466-2471.

Cruickshank, R., Duguid, J.P., Marmion, B.R., Swain, R.H.A. 1975. Medica Microbiology, $12^{\text {th }}$ Ed., vol.2, Churchill Livingstone, Edinburg, London.

Cunha, M.P.V., Oliveira, M.G.X., Oliveira, M.C.V., Silva, K.C., Gomes, C.R., Moreno, A.M., Knöbl, T. 2014. Virulence Profiles, Phylogenetic Background, and Antibiotic Resistance of Escherichia coli Isolated from Turkeys with Air sacculitis. The Scientific World J. Article ID 289024 (1-8).

David, G., Burch, S. 2000. Antimicrobial sensitivity patterns of UK chicken $E$. coli isolates. In Proceedings of European Association of Veterinary Pharmacology and Toxicology Congress, Jerusalem, Israel: 73-83.

Edward, P.R., Ewing, W.H. 1972. Edward and Ewing's identification of Enterobacteriacae, $3^{\text {rd }}$ Ed. Burgess, Minneapolis.

Ewers, C., Janssen, T., Kiessling, S., Philipp, H.C., Wieler, L.H. 2004. Molecular epidemiology of avian pathogenic Escherichia coli (APEC) isolated from colisepticemiae in poultry. 9. Vet. Microbiol. 104 (1-2): 91-101.

Ezzeldeen, N.A., Al Amary, K.F., Abdelmonem, M.A., El-Moez S.I., Abd el Aziz, M.F. 2013. Genotyping characterization of $E$. coli Egyptian isolates with special reference to drug resistance genes.

Finegold, S.M., Martin, W.J. 1982. Bailey and Scott's. Diagnostic Microbiology. $6^{\text {th }}$ Ed. The C.V. Mosby Company. St. Louis, Toronto, London.

Germon, P., Chen, Y.H., He, L., Blanco, J.E., Bree A., Schouler, C., Huang S.H., Moulin-schouleur, M. 2005. ibeA, a virulence factor of avian pathogenic Escherichia coli. Microbiology J. 151: 1179- 86.

Giovanardi, D., Campagnari, E., Ruffoni, L.S., Pesente, P., Ortali, G., Furlattini, V. 2005. Avian pathogenic Escherichia coli transmission from broiler breeders to their progeny in an integrated poultry production chain. Avian Pathol. J. 34: 313-318.

Gomis, S.M., Riddell, C., Potter, A.A., Allan, B.J. 2001. Phenotypic and genotypic characterization of virulence factors of Escherichia coli isolated from broiler chickens with simultaneous occurrence of cellulitis and other colibacillosis lesions. The Canadian Journal of Veterinary Research, 65 (1): 1-6.

Guerra, B. Junker, E. Schroeter, A. Malorny, B. Lehmann, S. Helmuth, R. 2003. Phenotypic and genotypic characterization of antimicrobial resistance in German E. coli isolates from cattle, swine and poultry. Antimicrobial Chemotherapy J. 52: 489-492.

Gyles, C.L. 2008. Antimicrobial resistance in selected bacteria from Poultry. Animal Health Research Reviews, J. 9(2): 149-158. 
Islam, M.T., Islam, M.A., Samad, M.A., Kabir, S.M.L. 2004. Characterization and antibiogram of Escherchia coli associated with mortality in broilers and ducklings in Bangladesh. Bangl. J.Vet. Med., 2 (1): 9-14.

Jeong, Y.W., Kim, T.E., Kim, J.H. Kwon, H.J. 2012. Pathotyping avian pathogenic Escherichia coli strains in Korea. Vet. Sci. J. 13(2):145- 152.

Jin, W., Zheng, Z., Zhang, Y. Qin, A., Shao H. Liu, Y., Wang, J. Wang, Q. 2008. Distribution of virulenceassociated genes of avian pathogenic Escherichia coli isolates in China. Agricultural Sciences in China, 7 (12): 1511-1515.

Kawano, M., Yaguchi, K., Osawa, R. 2006. Genotypic analyses of Escherichia coli isolated from chickens with colibacillosis and apparently healthy chickens in Japan. Microbiol Immunol J., 50: 961- 966.

Kitch, T.T., Jacobs, M.R., Appelbaum, P.C. 1994. Evaluation of RapID one system for identification of 379 strains in the family Enterobacteriaceae and oxidasenegative, gram-negative non fermenters. J. Clin. Microbiol.32: 931-934.

Kumar, A.D., Sarma, B.J., Rao, A.S., Mishra, S.K. 2003. Serogroups of Escherichia coli isolates from chickens and their antibiogram. Indian Journal of Poultry science, 38 (3): 270-273.

Le Bouguénec, C., Schouler, C. 2011. Sugar metabolism, an additional virulence factor in enterobacteria. International Journal of Medical Microbiology, 301 (1): 1-6.

Lee, J.H., Huang, M.Z., Wu, J.L., Tsai, W.C. 1994. Assessment of a new four-hour diagnostic Kit-RapID on E system for the identification of enteric bacteria. Chinese J. Microbiol. Immunol. 27:133-139

McPeake, S.J.W., Smyth, J.A., Ball, H. J. 2005.Characterization of avian pathogenic Escherichia coli (APEC) associated with colisepticaemia compared to faecal isolates from healthy birds. Vet Microbiol. J. 110: 245-253.

Mellata, M. 2013. Human and avian extra intestinal pathogenic

Escherichia coli: infections, zoonotic risks, and antibiotic resistance Trend. Foodborne Pathogens and Diseases, J. 10(11): 916-932.

Momtaz, H., Rahimi, E., Moshkelani, S. 2012. Molecular detection of antimicrobial resistance genes in $E$. coli isolated from slaughtered commercial chickens in Iran. Veterinarni Medicina. J. 57(4): 193197.

Nashwa, A.E., Mohamed, Kh. F., Nahla, A.H. 2010. Characterization of surface proteins of $E$. coli isolated from different Egyptian sources. Inter. J. of Microbiol., 1 (3):147-161.

Nazir, K.N.H. 2004. Molecular base of diversified Escherichia coli isolates potentiating antibiotic resistant pattern and compromising epidemiology. MsC. Department of Microbiology and Hygiene, Bangladesh University.

Norhan, K.A. 2011.Molecular studies on some virulence genes of $M$. gallisepticum and E. coli accused of respiratory disease in chickens.Ph.

D. Thesis, Department of Bacteriology, Mycology and Immunology, Zagazig University.

Ozawa, M., Harada, K., Kojima, A., Asai, T., Sameshima, T. 2008. Antimicrobial susceptibilities, serogroups, and molecular characterization of avian pathogenic Escherichia coli isolates in Japan. Avian Dis. J. 52: 392-397.

Pessanha R.P., Gontijo Filho, P.P. 2001. Uso de antimicrobianos como promotores de crescimento $\mathrm{e}$ resistência em isolados de Escherichia coli e de Enterobacteriaceae lactose-negativa 
da microflora fecal de frangos de corte. Arquivo Brasileiro de Medicina Veterinária e Zootecnia, 53: 111115.

Piddock, L.J.V. 1996. Does the use of antimicrobial agents in veterinary medicine and animal husbandry select antibiotic resistant bacteria the infect man and compromise antimicrobial chemotherapy? Antimicrobiol. Chemotherapy J. 38: 1-3.

Quinn, P.J., Markey, B.K., Carter, M.E., Donnelly, W.J.C., Leonard F.C., Maguire, D. 2002.Veterinary Microbiology and Microbial Disease. Iowa State Univ. Press, Blackwell Science Ltd: 84-96.

Rahimi, M. 2013. Antibioresistance Profile of Avian pathogenic Escherichia coli Isolates Recovered from Broiler Chicken Farms with Colibacillosis in Kermanshah Province, Iran. Global Veterinaria J. 10 (4): 447-452.

Rahman, M.B., Rahman, M., Rahman, A. 2008. Antibiogram and plasmid profile analysis of isolated E. coli from broiler and layer. Research Microbiol. J. 3: 82-90.

Raji, M., Adekeye, J., Kwaga, J., Bale, J., Henton, M. 2007. Serovars and

biochemical characterization of Escherichia coli isolated from colibacillosiscases and dead-in-shell embryos in poultry in Zaria-Nigeria. Veterinar ski Arhiv, 77(6): 495-505.

Rezk, M.M., Enany, M.E., Hanafy, M.S. 2010. Relationship between Oserogroup, virulence and plasmid profile in Escherichia coli isolated from diseased chickens. Journal of Food Safety, 30(3): 679-698.

Saberfar, E., Pourakbari, B., Chabokdavan, K., Dolatshahi, F. 2008. Antimicrobial Susceptibility of Escherichia coli Isolated from Iranian Broile r Chicken Flocks, 20052006. Journal of Applied Poultry Researches, 17: 302-304.

Saenz, Y. Zarazaga, M. Brinas, L. RuizLarrea, F. Van den Bogaard, A.
Stobberingh, E.E., Toress, C. 2003. Mutations in gyr $\mathrm{A}$ and par $\mathrm{C}$ genes in nalidixic acid resistant $E$. coli strains from food products, humans and animals. Antimicrobiol. Chemotherapy J. 51: 1001-1005.

Samanta, I., Joardar, S.N., Das, P.K. Das, P., Sar, T.K., Dutta, T.K., Bandyopadhyay, S., Batabyal, S. Isore, D. P. 2014. Virulence repertoire, characterization, and antibiotic resistance pattern analysis of E. coli isolated from backyard layers and their environment in India. Avian Dis. J. 58 (1): 39-45.

Sharada, I.R.S., Ruban, W., Thiageeswaran, I.M. 2010. Isolation, characterization and Antibiotic Resistance Pattern of Escherichia coli Isolated from Poultry. American-Eurasian Journal of Scientific Research 5(1):18-22. Shimaa, H.A., Mosalem 2013. Some Advanced Studies on avian pathogenic E. coli in broiler chickens at Sharkia governorate. M.V.Sc.

Thesis, Fac. Vet. Med. Zagazig Univ.

Teuber, M. 2001. Veterinary use and antibiotic resistance. Current Opinion in Microbiol. J. 4: 493-497.

Wafaa, M.A. Gad 2012. Occurrence of antibiotic resistance genes in E. coli serotypes isolated from broilers. M.V. SC. Thesis, Fac. Vet. Med. Zagazig Univ.

Wen-Jie, J., Zhi-Ming, Z., Yong-Zhi, Z., Ai-Jian, Q., Hong-Xia, S., Yue-Long, L., Jiao, W., Qian-Qian, W. 2008. Distribution of virulence-associated genes of avian pathogenic Escherichia coli isolates in China. Agricultural Sciences in China J. 7(12): 1511-1515.

Yaguchi, K., Ogitani, T., Osawa, R., Kawano, M., Kokumai, N., Kaneshig, E.T., Noro, T., Masubuchi, K., Shimizu, Y. 2007. Virulence factors of avian pathogenic Escherichia coli strains isolated from chickens with 
colisepticemia in Japan. Avian Dis J.51: 656-62.

Zhao, S., Maurer, J.J., Hubert, S., De Villena, J.F., McDermot, P.F., Meng, J., Ayers, S., English, L., White, D.G.
2005. Antimicrobial susceptibility and molecular characterization of avian pathogenic Escherichia coli isolates. Vet. Microbiol. J. 107 (3-4): 215-224. 